Article

\title{
Short Comments on the Application of Criteria for Identifying Ecologically or Biologically Significant Marine Areas (EBSAs)
}

\author{
Hao Huang ${ }^{1}$, Dongmei Tang ${ }^{2,3}$, Bin Chen ${ }^{1}$, Weiwen $\mathrm{Li}^{1, *}$, Danyun Ou ${ }^{1}$, Lei Wang ${ }^{1}$ and \\ Lina An ${ }^{1}$ \\ 1 Laboratory of Marine Biology and Ecology, Third Institute of Oceanography, Ministry of Natural Resources, \\ Xiamen 361005, Fujian, China; huanghao@tio.org.cn (H.H.); chenbin@tio.org.cn (B.C.); \\ oudanyun@tio.org.cn (D.O.); wanglei@tio.org.cn (L.W.); anlina@tio.org.cn (L.A.) \\ 2 Institute of South-South Cooperation and Development, Peking University, Beijing 100871, China; \\ tangdm2018@isscad.pku.edu.cn \\ 3 Department of Marine Strategy Planning and Economy, Ministry of Natural Resources, Beijing 100812, China \\ * Correspondence: liweiwen0207@163.com
}

Received: 6 November 2019; Accepted: 18 December 2019; Published: 23 December 2019

\begin{abstract}
In 2008, the Convention on Biological Diversity adopted seven criteria for identifying ecologically or biologically significant marine areas (EBSAs) for biodiversity conservation. Nine international workshops were held in which 209 areas and 38 potential areas were identified as meeting the EBSA criteria. This study analyzes the 209 identified areas and reveals that the use of the seven criteria in different workshops differed, so their scores are therefore not quantifiable. Furthermore, descriptions specific to criteria regarding areas having "special importance for the life-history stages of species" accounted for only $1.44 \%$ of the overall descriptions. Most descriptions regarding "vulnerability, fragility, sensitivity, or slow recovery" were almost contributed by the "importance of threatened, endangered, or declining species and/or habitats". These three criteria were based on scientific evidences and have been widely accepted by the public. Therefore, we would suggest the criteria of "special importance for the life-history stages of species" and the criteria of "vulnerability, fragility, sensitivity, or slow recovery" need further investigation for biodiversity conservation.
\end{abstract}

Keywords: ecologically or biologically significant marine areas (EBSAs); criteria; Convention on Biological Diversity (CBD)

\section{Introduction}

The United Nations (UN) Convention on Biological Diversity (CBD) defines biodiversity as "the variability among living organisms from all sources including inter alia, terrestrial, marine, and other aquatic ecosystems and the ecological complexes of which they are part. This includes diversity within species, between species, and of ecosystems" [1]. The Intergovernmental Panel on Climate Change (2002) defines the diversity of life at three levels: genetic, species, and ecosystem.

Human activities are changing biodiversity all over the world, thus imperiling the entire ecosystem [2]. The impacts of human activities are both direct and indirect. Many species are threatened with extinction due to the loss of available resources, and this situation is becoming increasingly serious [3-6]. There is growing concern about threats to biodiversity caused by climate crisis and overexploitation [7].

Sustainable use is defined as the use of resources in a way and at a rate that does not lead to their long-term decline but allows their potential to be maintained to meet the needs of present and 
future generations [8]. The sustainable use of marine biodiversity has been called for in a number of international conferences, such as the World Summit on Sustainable Development 2002, the UN General Assembly Resolution 57/141, CBD Aichi Target 11 and the UN Conference on Environment and Development (UNED) Rio+20 and Sustainable Development Goal 14.

The need for the conservation and sustainable use of biodiversity beyond national jurisdiction (BBNJ) is attracting increasing international attention, and the General Assembly decided to convene an Intergovernmental Conference (IGC) established by the resolution 72/249 which would require the establishment of an international legally binding instrument under the UN Convention on the Law of the Sea for the conservation and sustainable use of BBNJ. The first, second, and third sessions of the IGC of the BBNJ discussed area-based management tools (ABMTs), including marine protected areas (MPAs), and proposed 21 criteria for area designation such as "uniqueness" and "rarity" and so on. The participants concluded that the criteria failed to meet MPA requirements and that more restrictive protection measures are required.

The CBD signature commitment at the UNED in June 1992 indicated that the CBD will strive to ensure the sustainability of marine biodiversity [9]. It established a set of scientific criteria for identifying ecologically or biologically significant areas (EBSAs) that are considered to be priority areas to be conserved. An EBSA is an area of special importance with respect to its ecological or biological characteristics, which include all seabed habitats from the coast to deep ocean trenches, and any area of the water column from the surface to the abyss [10]. EBSAs are established based on seven criteria, including "uniqueness or rarity", "special importance for life-history stages of species", "importance for threatened, endangered or declining species and/or habitats", "vulnerability, fragility, sensitivity, or slow recovery", "biological productivity", "biological diversity", and "naturalness". Table 1 provides the details of the seven criteria.

Table 1. Seven criteria for an ecologically or biologically significant area (EBSA) [11].

\begin{tabular}{|c|c|c|}
\hline Number & Criteria & Definition \\
\hline $\mathrm{C} 1$ & Uniqueness or rarity & $\begin{array}{l}\text { The area contains either (i) unique (the only one of its } \\
\text { kind), rare (occurs only in few locations) or endemic } \\
\text { species, populations or communities; and/or (ii) } \\
\text { unique, rare or distinct, habitats or ecosystems; } \\
\text { and/or (iii) unique or unusual geomorphologic or } \\
\text { oceanographic features. }\end{array}$ \\
\hline $\mathrm{C} 2$ & $\begin{array}{l}\text { Special importance for life-history } \\
\text { stages of species }\end{array}$ & $\begin{array}{l}\text { Areas that are required for a population to survive } \\
\text { and thrive. }\end{array}$ \\
\hline $\mathrm{C} 3$ & $\begin{array}{l}\text { Importance for threatened, } \\
\text { endangered or declining species } \\
\text { and/or habitats }\end{array}$ & $\begin{array}{l}\text { Areas containing habitats for the survival and } \\
\text { recovery of endangered, threatened or declining } \\
\text { species or areas with significant assemblages of } \\
\text { such species. }\end{array}$ \\
\hline $\mathrm{C} 4$ & $\begin{array}{l}\text { Vulnerability, fragility, sensitivity, } \\
\text { or slow recovery }\end{array}$ & $\begin{array}{l}\text { Areas that contain a relatively high proportion of } \\
\text { sensitive habitats, biotopes or species that are } \\
\text { functionally fragile (highly susceptible to } \\
\text { degradation or depletion by human activity or by } \\
\text { natural events) or with slow recovery. }\end{array}$ \\
\hline C5 & Biological productivity & $\begin{array}{l}\text { Areas containing species, populations or } \\
\text { communities with comparatively higher natural } \\
\text { biological productivity. }\end{array}$ \\
\hline C6 & Biological diversity & $\begin{array}{l}\text { Areas containing comparatively higher diversity of } \\
\text { ecosystems, habitats, communities or species, or has } \\
\text { higher genetic diversity. }\end{array}$ \\
\hline $\mathrm{C} 7$ & Naturalness & $\begin{array}{l}\text { Areas with a comparatively higher degree of } \\
\text { naturalness as a result of the lack of, or low level of, } \\
\text { human-induced disturbance or degradation. }\end{array}$ \\
\hline
\end{tabular}


In this paper, we analyze the EBSAs criteria used by the CBD to describe areas that meet one or more of the seven criteria in the marine environment. Based on these seven EBSA criteria, a very large percentage of the oceans in the world have been defined by intergovernmental workshops as meeting the requirements [12]. Yet the EBSAs only represent the marine areas and their surroundings that are considered by the international community to be of greater importance for biodiversity conservation [13]. Here, we present the results of our analysis of the nine intergovernmental workshops in which 209 EBSAs were defined [14-22]. These results indicate that more knowledge is needed about the criteria of "special importance for life-history stages of species" and the criteria of "vulnerability, fragility, sensitivity, or slow recovery".

\section{Development of EBSA Criteria}

The CBD, the UN Food and Agriculture Organization (FAO), and the International Maritime Organization (IMO) have established a set of criteria for identifying areas for urgent protection in their respective fields [23]. However, the CBD used these criteria to identify areas suitable for designation as MPAs or part of an MPA networks [24], while the FAO and IMO applied these criteria to protect areas in which human activities might diminish biodiversity. A review of these criteria provides key information for establishing criteria for the identification of EBSAs on the high seas. This was the focus of the first expert workshop in which participants systematically discussed ecologically and biologically significant areas beyond national jurisdiction (ABNJ) [24]. From this review, six criteria were defined, including "uniqueness", "life history stages", "vulnerability", "productivity", "biological diversity", and "naturalness".

In 2006, the 8th Conference of Parties (COP 8) was held in Montecatini, Italy, where participants discussed the CBD's role regarding ABNJ. It was suggested that the EBSA criteria need to be improved by taking into consideration the ecosystem and a precautionary approach [25]. EBSAs were identified as a part of expert processes, which may result in biased results depending on the dialogues and actions carried out. COP 8 called for an expert workshop to establish a consolidated set of EBSA criteria [26]. When the CBD expert workshop was held in the Azores in 2007, the EBSA criteria were reviewed and refined to seven criteria, including "uniqueness or rarity", "special importance for the life-history of species", "importance for threatened, endangered or declining species and/or habitats", "vulnerability, fragility, sensitivity, or slow recovery", "biological productivity", "biological diversity", and "naturalness".

A marine protected area (MPA) network is a network of marine protected areas or marine reserves. A marine protected area network can be defined as "a collection of individual MPAs or reserves operating cooperatively and synergistically, at various spatial scales, and with a range of protection levels that are designed to meet objectives that a single reserve cannot achieve" [27]. The criteria for the MPA network were discussed during the CBD 2007 expert workshop held in the Azores, and five scientific criteria were defined for the MPA network that included EBSAs. The five criteria are representativity, connectivity, replicated ecological features, and adequate and viable sites [28]. However, this does not mean that all EBSAs or extensions of established EBSAs can become MPAs. Rather, these are just the factors contributing to the MPA candidature.

The 9th COP was held in Germany in 2008, during which the seven EBSA criteria and five MPA network criteria were adopted by the CBD in Decision IX/20. This means that the EBSA criteria may now be applied in practice. These criteria can guide the identification of marine areas in need of protection in open-sea and deep-sea habitats [29]. A follow-up CBD expert workshop held in Ottawa in 2009 called for providing technical guidance for identifying areas in need of protection [30]. This expert workshop focused on the areas identified as being in need of protection, especially in ABNJ, although these criteria have some similarity with those of other inter-governmental organizations (IGOs) [31-33] and non-governmental organizations (NGOs) [34,35]. The criteria applied by these organizations consider special factors such as species vulnerability to specific human activities [36]. 


\section{Areas that Meet EBSA Criteria}

The CBD's 10th COP hosted by Japan adopted Aichi Biodiversity Targets such as target 6 (i.e., to achieve sustainable fisheries by 2020) and target 11 (i.e., to protect at least $10 \%$ of the coast and ABNJ by 2020), which replaces the goal of protecting 10\% of the CBD MPAs by $2012[37,38]$. To achieve these goals, the CBD organized nine regional EBSA workshops to describe areas that meet the EBSA criteria. From 2012 to 2014, these nine regional EBSA workshops have fully described 209 areas that meet the EBSAss criteria (Table 2). All the original reports came from the nine regional EBSA workshops' final reports [14-22].

Table 2. EBSAs described by Convention on Biological Diversity (CBD) regional workshop.

\begin{tabular}{lllll}
\hline \multicolumn{1}{c}{ Regional Workshop on EBSAs } & \multicolumn{1}{c}{ Data Started } & \multicolumn{1}{c}{$\begin{array}{c}\text { Number of } \\
\text { EBSAs Described }\end{array}$} & Host City & Reference \\
\hline North Pacific Ocean & 25 February 2013 & 20 & Moscow & {$[14]$} \\
Western South Pacific Ocean & 30 April 2012 & 26 & Montreal & {$[15]$} \\
Eastern Tropical and Temperate Pacific & 28 August 2012 & 21 & Galapagos Islands & {$[16]$} \\
Southern Indian Ocean & 31 July 2012 & 39 & Mauritius & {$[17]$} \\
Arctic Region & 3 March 2014 & 12 & Helsinki & {$[18]$} \\
Mediterranean Region & 7 April 2014 & 17 & Málaga & {$[19]$} \\
South-eastern Atlantic & 8 April 2013 & 45 & Swakopmund & {$[20]$} \\
Wider Caribbean and Western & 30 April 2012 & 22 & Montreal & {$[21]$} \\
Mid-Atlantic & 24 March 2014 & 7 & Montreal & {$[22]$} \\
North-west Atlantic & & & & \\
\hline
\end{tabular}

The South Indian Ocean has 39 areas that meet the EBSAs criteria, whereas the Northwest Atlantic has just seven areas (Table 2). All the information pertaining to the seven EBSAs criteria was reviewed during the regional workshops against each of the ESBAs criteria and classified as either high $(\mathrm{H}$, the highest rating), medium $(\mathrm{M}$, the medium rating), low ( $\mathrm{L}$, the lowest rating), or gap (gap, without the knowledge). And all the classified EBSAs criteria were judged by the regional workshop. Traditional knowledge contributed to the assessments regarding the seven EBSAs criteria, as did scientific information. The percentages of the $\mathrm{H}, \mathrm{M}, \mathrm{L}$, and gap classifications varied between the different criteria and regions (Table 3). In the North Pacific Ocean region workshop (Table 3), for instance, the percentage of $\mathrm{H}$ for $\mathrm{C} 5$ was 0.85 , whereas it was $0.40 \mathrm{for} \mathrm{C}$, which indicated that the North Pacific Ocean region workshop paid much more attention to the conservation of biological productivity [39]. Overall, the $\mathrm{H}$ classification for $\mathrm{C} 1$ ranges from 0.450 to 0.857 , with a mean of 0.632 , and the means for C2, C3, C4, C5, C6, and C7 are 0.679, 0.574, 0.464, 0.517, 0.498, and 0.297, respectively (Table 4).

The authors compared the descriptions by the regional workshop under the CBD with the criteria definitions provided by the CBD. When the description meets its definition, we judged it as specifically described for the criterion. When its description meets a part of the definition, and a part meets other criterion, we judged it as a partial description for its criterion. When its description did not meet with its definition, but meets with another criterion, we judged it as mainly described by another criterion. When its description did not meet its definition, and did not meet with any other criterion, we judged that it did not meet its criterion. We judged a description lacking any information as an information gap.

However, the knowledge of C2, C3, and C4 differ (Table 4). More than $80 \%$ of $\mathrm{C} 2$ is described by C3 (Table 5); for example, the aggregation area of the Northeastern Pacific White Shark is described in C2 as follows: Area appears to exhibit gender-based behaviors for its mating, and feeds on squid. In C3, this species is described as follows: White sharks have been listed for international protection under the Convention on International Trade in Endangered Species (CITES) and the International Union for the Conservation of Nature (IUCN), and these areas are significant for the Northeastern Pacific population's aggregation. We consider C2 to be mainly described by C3. Furthermore, $10 \%$ of its descriptions did not match its own requirements. For instance, the Juan de Fuca Ridge hydrothermal vents (North Pacific Ocean) are described as having special importance for the life-history stages of species as follows: Production based on chemosynthesis provides food resources for the specialized fauna associated with hydrothermal vents, which indicates that sulfur-related metabolism is crucial to vent ecosystems, which we categorize as not meeting C2. 
Table 3. Data analysis for nine regions.

\begin{tabular}{|c|c|c|c|c|c|c|c|c|}
\hline Region & Level & $\begin{array}{l}\text { Uniqueness } \\
\text { or Rarity }\end{array}$ & $\begin{array}{l}\text { Special Importance for } \\
\text { Life-History Stages } \\
\text { of Species }\end{array}$ & $\begin{array}{l}\text { Importance for Threatened, } \\
\text { Endangered or Declining } \\
\text { Species and/or Habitats }\end{array}$ & $\begin{array}{c}\text { Vulnerability, } \\
\text { Fragility, Sensitivity, } \\
\text { or Slow Recovery }\end{array}$ & $\begin{array}{c}\text { Biological } \\
\text { Productivity }\end{array}$ & $\begin{array}{l}\text { Biological } \\
\text { Diversity }\end{array}$ & Naturalness \\
\hline \multirow{4}{*}{$\begin{array}{l}\text { North Pacific } \\
\text { Ocean [14] }\end{array}$} & $\mathrm{H}$ & 9 & 14 & 13 & 12 & 17 & 13 & 8 \\
\hline & $\mathrm{M}$ & 5 & 5 & 1 & 6 & 3 & 5 & 7 \\
\hline & $\mathrm{L}$ & 5 & 1 & 3 & 2 & 0 & 2 & 5 \\
\hline & Gap & 1 & 0 & 3 & 0 & 0 & 0 & 0 \\
\hline \multirow{4}{*}{$\begin{array}{l}\text { Western South } \\
\text { Pacific [15] }\end{array}$} & $\mathrm{H}$ & 13 & 14 & 10 & 9 & 8 & 10 & 9 \\
\hline & $\mathrm{M}$ & 10 & 3 & 11 & 9 & 10 & 8 & 10 \\
\hline & $\mathrm{L}$ & 2 & 3 & 1 & 1 & 4 & 5 & 2 \\
\hline & Gap & 1 & 6 & 4 & 7 & 4 & 3 & 5 \\
\hline \multirow{4}{*}{$\begin{array}{l}\text { Eastern Tropical } \\
\text { and Temperate } \\
\text { Pacific [16] }\end{array}$} & $\mathrm{H}$ & 17 & 19 & 12 & 7 & 13 & 10 & 2 \\
\hline & $\mathrm{M}$ & 3 & 1 & 7 & 9 & 5 & 7 & 10 \\
\hline & $\mathrm{L}$ & 1 & 1 & 1 & 3 & 1 & 1 & 5 \\
\hline & Gap & 0 & 0 & 1 & 2 & 2 & 3 & 4 \\
\hline \multirow{4}{*}{$\begin{array}{l}\text { Southern Indian } \\
\text { Ocean [17] }\end{array}$} & $\mathrm{H}$ & 25 & 24 & 19 & 14 & 20 & 19 & 13 \\
\hline & M & 12 & 11 & 14 & 20 & 9 & 12 & 11 \\
\hline & L & 1 & 1 & 1 & 3 & 4 & 1 & 12 \\
\hline & Gap & 1 & 3 & 5 & 2 & 6 & 7 & 3 \\
\hline \multirow{4}{*}{ Arctic Region [18] } & $\mathrm{H}$ & 6 & 11 & 5 & 10 & 10 & 4 & 8 \\
\hline & $\mathrm{M}$ & 6 & 1 & 6 & 2 & 1 & 4 & 4 \\
\hline & $\mathrm{L}$ & 0 & 0 & 0 & 0 & 1 & 2 & 0 \\
\hline & Gap & 0 & 0 & 1 & 0 & 0 & 2 & 0 \\
\hline \multirow{4}{*}{$\begin{array}{c}\text { Mediterranean } \\
\text { Region [19] }\end{array}$} & $\mathrm{H}$ & 12 & 14 & 15 & 12 & 8 & 10 & 2 \\
\hline & $\mathrm{M}$ & 5 & 3 & 2 & 4 & 5 & 5 & 8 \\
\hline & L & 0 & 0 & 0 & 1 & 1 & 0 & 4 \\
\hline & Gap & 0 & 0 & 0 & 0 & 2 & 5 & 3 \\
\hline \multirow{4}{*}{$\begin{array}{l}\text { South-eastern } \\
\text { Atlantic [20] }\end{array}$} & $\mathrm{H}$ & 29 & 28 & 27 & 15 & 21 & 16 & 8 \\
\hline & $\mathrm{M}$ & 11 & 14 & 14 & 27 & 20 & 23 & 19 \\
\hline & $\mathrm{L}$ & 5 & 1 & 2 & 1 & 1 & 3 & 12 \\
\hline & Gap & 0 & 2 & 2 & 2 & 3 & 3 & 6 \\
\hline \multirow{4}{*}{$\begin{array}{l}\text { Wider Caribbean } \\
\text { and Western } \\
\text { Mid-Atlantic [21] }\end{array}$} & $\mathrm{H}$ & 15 & 14 & 17 & 15 & 9 & 17 & 10 \\
\hline & $\mathrm{M}$ & 6 & 5 & 4 & 7 & 8 & 3 & 9 \\
\hline & $\mathrm{L}$ & 1 & 0 & 1 & 0 & 2 & 2 & 3 \\
\hline & Gap & 0 & 3 & 0 & 0 & 3 & 0 & 0 \\
\hline \multirow{4}{*}{$\begin{array}{l}\text { North-west } \\
\text { Atlantic [22] }\end{array}$} & $\mathrm{H}$ & 6 & 4 & 2 & 3 & 2 & 5 & 2 \\
\hline & M & 1 & 2 & 1 & 4 & 2 & 1 & 4 \\
\hline & $\mathrm{L}$ & 0 & 0 & 0 & 0 & 2 & 1 & 1 \\
\hline & Gap & 0 & 1 & 4 & 0 & 1 & 0 & 0 \\
\hline
\end{tabular}


Table 4. Classification of all 209 areas with respect to EBSA criteria.

\begin{tabular}{|c|c|c|c|c|c|c|c|}
\hline Level & $\begin{array}{l}\text { Uniqueness or } \\
\text { Rarity }\end{array}$ & $\begin{array}{l}\text { Special Importance } \\
\text { for Life-History } \\
\text { Stages of Species }\end{array}$ & $\begin{array}{c}\text { Importance for } \\
\text { Threatened, Endangered } \\
\text { or Declining Species } \\
\text { and/or Habitats }\end{array}$ & $\begin{array}{l}\text { Vulnerability, } \\
\text { Fragility, Sensitivity, } \\
\text { or Slow Recovery }\end{array}$ & $\begin{array}{l}\text { Biological } \\
\text { Productivity }\end{array}$ & $\begin{array}{l}\text { Biological } \\
\text { Diversity }\end{array}$ & Naturalness \\
\hline $\mathrm{H}$ & 132 & 142 & 120 & 97 & 108 & 104 & 62 \\
\hline M & 59 & 45 & 60 & 88 & 63 & 68 & 82 \\
\hline $\mathrm{L}$ & 15 & 7 & 9 & 11 & 16 & 17 & 44 \\
\hline Gap & 3 & 15 & 20 & 13 & 22 & 20 & 21 \\
\hline H Ratio & $\begin{array}{c}0.632 \\
(0.450,0.857)\end{array}$ & $\begin{array}{c}0.679 \\
(0.538,0.917)\end{array}$ & $\begin{array}{c}0.574 \\
(0.286,0.882)\end{array}$ & $\begin{array}{c}0.464 \\
(0.333,0.833)\end{array}$ & $\begin{array}{c}0.517 \\
(0.286,0.850)\end{array}$ & $\begin{array}{c}0.498 \\
(0.333,0.773)\end{array}$ & $\begin{array}{c}0.297 \\
(0.095,0.667)\end{array}$ \\
\hline
\end{tabular}


Table 5. Data analysis for criteria C2 and C3.

\begin{tabular}{lll}
\hline Criteria Description & Number & Ratio \\
\hline C2 mainly described by C3 & 85 & 0.4067 \\
C2 partly described by C3 & 86 & 0.4163 \\
Does not meet C2 & 19 & 0.0909 \\
Gap & 15 & 0.0718 \\
Specifically describes C2 & 3 & 0.0144 \\
Total & 208 & 1.0000 \\
\hline
\end{tabular}

Similarly, we counted the number of detailed descriptions and adoption frequency of this indicator in the 209 EBSAs and found that about $39.9 \%$ of C4 was mainly described by C3 (Table 6). For example, the Guaymas Basin hydrothermal vents are described in $\mathrm{C} 3$ as follows: Hydrothermal vents in the Guaymas Basin are important to abyssal species, and commercial activities would threaten these species. In C4, they are described as follows: Hydrothermal-vent metazoan species are a long-lived, low-productivity species, which makes them vulnerable to deep sea fishery activities in this region. We therefore categorized $\mathrm{C} 4$ as being described by $\mathrm{C} 3$. The knowledge of $\mathrm{C} 2$ and $\mathrm{C} 4$ are poorly known, and "threatened, endangered or declining species and/or habitats" yielded more information. The description of these criteria included information of "threatened, endangered or declining species and/or habitats".

Table 6. Data analysis for the C3 and C4.

\begin{tabular}{lcc}
\hline Criteria Description & Number & Ratio \\
\hline C4 mainly described by C3 & 83 & 0.3990 \\
C4 partly described by C3 & 34 & 0.1635 \\
Does not meet C4 & 56 & 0.2692 \\
Gap & 14 & 0.0673 \\
Specifically describes C4 & 21 & 0.1010 \\
Total & 208 & 1.0000 \\
\hline
\end{tabular}

\section{Discussion}

\subsection{Relationship with Other IGOs/NGOs/Processes}

Currently, many IGOs and environmental NGOs have put forward criteria for areas that need enhanced management or conservation. However, different IGOs and environmental NGOs have been established for different purposes and are playing different roles. The FAO, for instance, focused its criteria on the identification of vulnerable marine ecosystem (VMEs) to prevent vulnerable habitats and ecosystems on the sea floor from bottom fishing activities [31]. The IUCN established its criteria with respect to key biodiversity areas (KBAs) for the protection of areas that contribute significantly to the global persistence of biodiversity, including terrestrial, freshwater, and marine ecosystems [40]. The IMO seeks to protect vulnerable marine areas within a nation's or state's exclusive economic zone (referred to as particularly sensitive sea areas (PSSAs)) from damage by international maritime activities [41]. Important bird and biodiversity areas (IBAs) are those identified by BirdLife International for the protection of bird populations and general global biodiversity [42].

The CBD adopted its seven criteria to identify EBSAs for the conservation of biodiversity, firstly applied within the exclusive economic zone, but with the hopes of extending its areas to the high seas and deep sea. The sustainability of the marine biological diversity of ABNJs has become a hot topic of debate by members of the UN and NGOs. The issue of ABMTs that addresses marine protected areas (ABMT/MPAs) has become contentious regarding the terms "uniqueness", "rarity", "special importance for life-history stage of species", " importance for threatened, endangered or declining species and/or habitats", " vulnerability", " fragility", "sensitivity, or slow recovery", "productivity", biodiversity", " naturalness", " representativeness", and "dependency", as well as "connectivity", 
"environmental processes" and "economic and social factors". These criteria are matters of debate in many organizations (Table 7). The objective of ABMT/MPAs is the conservation and the sustainable use of BBNJ, which is very similar to the objective of EBSAs. Yet inevitably some of the EBSA criteria were mixed up when applied in practice.

Table 7. Correspondence between the CBD criteria and the criteria used by inter-governmental organizations (IGOs) and environmental non-governmental organizations (NGOs).

\begin{tabular}{lcccccc}
\hline Organizations & UN & CBD & FAO & IUCN & IMO & BirdLife \\
\hline Site criteria & ABMTs & EBSAs & VMEs & KBAs & PSSAs & IBA \\
Uniqueness & (MPA) & $\sqrt{ }$ & $\sqrt{ }$ & $\sqrt{ }$ & $\sqrt{ }$ & $\sqrt{ }$ \\
Rarity & $\sqrt{ }$ & $\sqrt{ }$ & $\sqrt{ }$ & $\sqrt{ }$ & $\sqrt{ }$ & $\sqrt{ }$ \\
Special importance for life-history & $\sqrt{ }$ & $\sqrt{ }$ & $\sqrt{ }$ & $\sqrt{ }$ & $\sqrt{ }$ & $\sqrt{ }$ \\
stage of species & $\sqrt{ }$ & $\sqrt{ }$ & $\sqrt{ }$ & $\sqrt{ }$ & $\sqrt{ }$ & $\sqrt{ }$ \\
Importance for threatened, endangered & $\sqrt{ }$ & $\sqrt{ }$ & $\sqrt{ }$ & $\sqrt{ }$ & $\sqrt{ }$ & \\
or declining species and/or habitats & $\sqrt{ }$ & $\sqrt{ }$ & $\sqrt{ }$ & $\sqrt{ }$ & $\sqrt{ }$ & \\
Vulnerability, & $\sqrt{ }$ & $\sqrt{ }$ & $\sqrt{ }$ & $\sqrt{ }$ & $\sqrt{ }$ & \\
fragility, & $\sqrt{ }$ & $\sqrt{ }$ & & & $\sqrt{ }$ & \\
sensitivity, or slow recovery & $\sqrt{ }$ & $\sqrt{ }$ & & $\sqrt{ }$ & $\sqrt{ }$ & \\
Productivity & $\sqrt{ }$ & $\sqrt{ }$ & & & $\sqrt{ }$ & \\
Biodiversity & $\sqrt{ }$ & & & & $\sqrt{ }$ & \\
Naturalness & $\sqrt{ }$ & & & & & \\
Representativeness & $\sqrt{ }$ & & &
\end{tabular}

Abbreviations: UN, United Nations; CBD, Convention on Biological Diversity; FAO, food and agriculture organization; IUCN, International Union for the Conservation of Nature; IMO, International Maritime Organization; ABMTs, area-based management tools; MPA, marine protected areas; VMEs, vulnerable marine ecosystem; KBAs, key biodiversity areas; PSSAs, particularly sensitive sea areas.

\subsection{Application of Criteria of "Special Importance for Life-History Stages of Species"}

The definition of an area of special importance for life-history stages of species is one that is required for a population to survive and thrive [11]. The criteria originally established for biodiversity conservation within exclusive economic zones were well defined, and the scientific biodiversity surveys for a nation or state's exclusive economic zone were well conducted. As such, many factors of special importance for the life-history stages of species have been well studied. However, this includes most species of high economic value or those that are threatened, endangered or in decline. Species with less economic value and by-catch species are of less concern, so it presented that $\mathrm{C} 2$ mainly described by C3 had a high ratio of $40.67 \%$ (Table 5). Scientific management measures were based on the protected objective, and the benefits of protected areas depend on its compliance, and its protection goals, such as no-trawling areas would be beneficial for the recovery of fishery stocks [43,44]. However, Adriatic areas not only protect marine mammals and seabirds, but also protect the critical benthic habitats for their specific goals, well known data, and approaches in the selected areas [45]. In addition, Adriatic areas are beyond the current EBSAs suggested by the CBD [46,47]. The conservation of specific goals would be protecting its ecosystem so as to achieve a better management result [44]. Thus, some species that have no economic value may still play important roles in the ecosystem, such as secondary producers or small fishes, and the ratio of their specific description was as low as $1.44 \%$ (Table 5).

The effective determination of factors of special importance for the life-history stages of species will require extensive and in-depth surveys and data collection to support the conclusions drawn. Threatened, endangered or declining species are of key concern to marine protected species, thus information about these species is well known. To address the lack of knowledge about most species, the description of areas that meet the EBAS criteria is mostly included in the criteria of "importance for threatened, endangered or declining species and/or habitats" (Table 5). Therefore, the application of the criteria of "special importance for life-history stages of species" seems much less practical. Shall we 
then pay less attention to these criteria until we learn more about what constitutes special importance for the life-history stages of most species?

\subsection{Application of the Criteria "Importance for Threatened, Endangered or Declining Species and/or Habitats"}

The definition of an area of importance for threatened, endangered or declining species and/or habitats is one that serves as a habitat for the survival and recovery of endangered, threatened or declining species or an area with significant assemblages of such species. Threatened, endangered or declining species and/or habitats easily become extinct and/or disappear under human activities, and their need for protection is urgent. At the international level, the IUCN's Red List of threatened species includes more than 500 species that require urgent protection. At the national level, many levels of marine protection areas have been established. China is a country rich in biodiversity, with a global biodiversity ranking of eight. At the same time, China's biodiversity is under serious threat [48]. As such, the government of China keeps a watchful eye on marine biodiversity protection. The "List of Wildlife Under Special State Protection", "China's Red Book on Endangered Animals", and "The Red List of Chinese Species" provide details of the species that need protection. Furthermore, an increasing number of MPAs have been assessed to enable the protection of marine biodiversity and habitats. In China, marine species protection is being addressed at the local, provincial, and national levels. Species protected at the national level include all those identified at the provincial and local levels, and the protection of most native species is restricted to the provincial and local levels. After long and hard work, threatened, endangered and declining species and/or habitats are now well protected and species that were in decline have begun to recover.

\subsection{Application of the Criteria "Vulnerability, Fragility, Sensitivity, or Slow Recovery"}

The definition of areas characterized by vulnerability, fragility, sensitivity, or slow recovery are those that contain a relatively high proportion of sensitive habitats, biotopes or species that are functionally fragile (highly susceptible to degradation or depletion by human activity or by natural events) or prone to slow recovery [49]. This definition emphasizes the resilience of species or habitats to physical, chemical or biological perturbations. Cold-water coral reefs are slow to recover and are highly sensitive to bottom trawling as well as the benthic ecosystem [31]. These criteria have been well assessed under the FAO's VME designations, which specify the need to protect benthic ecosystems and cold-water coral reefs. First, the areas suitable for the growth of cold coral reefs are small. Second, our knowledge of benthic ecosystems should be based on extensive and in-depth surveys. In this regard, bottom fishery logs have been well recorded by various countries along the North Pacific Ocean; the biology of marine fisheries and their environments have also been well studied, and an annual VME technical workshop has been attended by a range of international experts. As a result, there has been an accumulation of knowledge of benthic ecosystems that provides a scientific basis for VME protection. Scientists and marine managers have focused much attention on cold coral reefs and long-live species that are threatened, endangered or declining. However, with the exception of coral reefs, the relationship of biodiversity to vulnerability, fragility, sensitivity, or slow recovery is poorly known. A statistical analysis indicated that C4 mainly described by C3 could have a ratio as high as $39.90 \%$ (Table 6). In deep-sea, new species increased with the sampling frequency, proving it to have a rich biodiversity but low productive area [50]. For the scientific community in the near-shore, information on benthic assemblages is always achieved from bottom trawling and dredges. So, the studies on these samples offer irreplaceable taxonomic data but often these data are wasted owing to the lack of adequate taxonomic competences and few details are recorded about species interactions. As such, descriptions of these criteria for EBSAs are mostly addressed by the criterion "importance for threatened, endangered or declining species and/or habitats". To effectively guide the selection of EBSAs, this criterion has yet to be adequately defined and we would not consider it to be an effective criterion until we obtain greater knowledge of the relationship between vulnerability, fragility, sensitivity, or slow recovery and biodiversity. 


\section{Conclusions}

In this study, we analyzed 209 areas that meet the EBSA requirements, as defined in nine CBD workshops. The results revealed that the use of the seven criteria in the different workshops was not consistent, so their scores could not be quantified for use in an index. Furthermore, descriptions of the criteria of special importance for the life-history stages of species account for only $1.44 \%$ of specific descriptions for the knowledge of this information. Therefore, more than $80 \%$ of $\mathrm{C} 2$ being described by $\mathrm{C} 3$, and about $39.9 \%$ of $\mathrm{C} 4$ being described by C3. C2 and C4 may benefit from biodiversity conservation, but to our knowledge, $\mathrm{C} 2$ and $\mathrm{C} 4$ are so poor that we would recommend paying much more attention to the "special importance for life history of species" and the "vulnerability, fragility, sensitivity, slow recovery". In addition, the marine protected experts calling the marine protected areas network to instead the signal marine protected area that it would be much more effective. Marine protected areas network required to identify the areas which not only protected the "importance for threatened, endangered or declining species and/or habitats" but also protected the "special importance for life history of species" (some valueless species) and the "vulnerability, fragility, sensitivity, or slow recovery" (e.g., benthic assemblages). In the short term, all of these criteria are significant for biodiversity protection which is based on the best available scientific information, such that a quantifiable index is needed to assess their relative importance.

Author Contributions: Conceptualization, W.L. and L.A.; methodology, W.L.; validation, H.H., B.C. and L.W.; formal analysis, D.T.; investigation, H.H., D.T.; data curation, D.O.; writing-original draft preparation, H.H.; writing-review and editing, D.T., B.C. and W.L.; supervision, W.L.; project administration, W.L. and D.O. All authors have read and agreed to the published version of the manuscript.

Funding: This research was funded by the National Key Research and Development Program of China, No. 2018YFC0507205 and Monitoring and Protection of Ecology and Environment in the Eastern Pacific Ocean (No.DY135-E2-5); a supporting project of the Scientific Research Foundation of the Ministry of Natural Resources for Marine Biodiversity of Areas Beyond National Jurisdiction, No, HC180701; as well as the National Basic Research Program (973 program) of China, No. 2015CB452902; the Marine Public Welfare Project of China, No. 201505009 and the Natural Sciences Foundation of China, No. 40706042."

Acknowledgments: This work was supported by a project sponsored. We would also like to thank the reviewers who makes contribution for improving this manuscript and International Science Editing (http: //www.internationalscienceediting.com) for editing this manuscript.

Conflicts of Interest: The authors declare no conflict of interest.

\section{References}

1. Suárez, A.G.; Garraway, E.; Vilamajó, D.; Mujica, L.; Gerhartz, J.; Capote, R.T.; Blake, N. Climate Change Impacts on Terrestrial Biodiveristy Report of Working Group III, Climate Change and Biodiversity in Caribbean Island Capote; Natalie Blake CANARI Technical Report No. 383; Caribbean Natural Resources Institute: Eltham, London, 2008.

2. Cardinale, B.J.; Duffy, J.E.; Gonzalez, A.; Hooper, D.U.; Perrings, C.; Venail, P.; Narwani, A.; Mace, G.M.; Tilman, D.; Wardle, D.A.; et al. Biodiversity loss and its impact on humanity. Nature 2012, 486, 59-67. [CrossRef] [PubMed]

3. Ehrlich, P.R. Energy Use and Biodiversity Loss. Philos. Trans. R. Soc. B Biol. Sci. 1994, 344, 99-104.

4. Myers, N. Two key challenges for biodiversity: Discontinuities and synergisms. Biodivers. Conserv. 1996, 5, 1025-1034. [CrossRef]

5. Pimm, S.L.; Russell, G.J.; Gittleman, J.L.; Brooks, T.M. The future of biodiversity. Science 1995, 269, $347-350$. [CrossRef] [PubMed]

6. Wilson, E.O. The Diversity of Life; Harvard University Press: Cambridge, CA, USA; London, UK; Macmillan: New York, NY, USA, 1992.

7. Maxwell, S.L.; Fuller, R.A.; Brooks, T.M.; Watson, J.E.M. Biodiversity: The ravages of guns, nets and bulldozers. Nature 2016, 536, 143-145. [CrossRef] [PubMed]

8. Carapuço, M.M. Sustainable Use; Springer: Dordrecht, The Netherlands, 2016. 
9. UN. United Nations Conference on Environment and Development, Agenda 21.Rio De. Janerio, Brazil, 1 December 1992. Section 17.85. Available online: https:/sustainabledevelopment.un.org/content/documents/ Agenda21.pdf (accessed on 22 December 2019).

10. Johnson, D.E.; Froján, C.B.; Turner, P.J.; Weaver, P.; Gunn, V.; Dunn, D.C.; Halpin, P.; Bax, N.J.; Dunstan, P.K. Reviewing the EBSA process: Improving on success. Mar. Policy 2018, 88, 75-85. [CrossRef]

11. CBD. Training Manual for the Description of Ecologically and Biologically Significant Areas (ebsas) in Open-Ocean Waters and Deepsea Habitats; UNEP/CBD/SBSTTA/16/INF/9; CBD: Montreal, QC, Canada, 3 May 2012.

12. Dunn, D.C.; Ardron, J.; Bax, N.; Bernal, P.; Cleary, J.; Cresswell, I.; Kaschner, K. The Convention on Biological Diversity's Ecologically or Biologically Significant Areas: Origins, development, and current status. Mar. Policy 2014, 49, 137-145. [CrossRef]

13. Bax, N.J.; Cleary, J.; Donnelly, B.; Dunn, D.C.; Dunstan, P.K.; Fuller, M.; Halpin, P.N. Results of efforts by the Convention on Biological Diversity to describe ecologically or biologically significant marine areas. Conserv. Biol. 2016, 30, 571-581. [CrossRef] [PubMed]

14. CBD. Report of the North Pacific Regional Workshop to Facilitate the Description of Ecologically or Biologically Significant Marine Areas. UNEP/CBD/RW/EBSA/NP/1/4. In Proceedings of the North Pacific Regional Workshop to Facilitate the Descr Iption of Ecologically or Biologically Significant Marine Areas, Moscow, Russia, 25 February-1 March 2013; CBD: Montreal, QC, Canada.

15. CBD. Report of the Western South Pacific Regional Workshop to Facilitate the Description of Ecologically or Biologically Significant Marine Areas; UNEP/CBD/SBSTTA/16/INF/6; CBD: Montreal, QC, Canada, 11 April 2012.

16. CBD. Report of the Eastern Tropical and Temperate Pacific Regional Workshop to Facilitate the Description of Ecologically or Biologically Significant Marine Areas; UNEP/CBD/RW/EBSA/ETTP/1/4; CBD: Montreal, QC, Canada, 23 June 2013.

17. CBD. Report of the Southern Indian Ocean Regional Workshop to Facilitate the Description of Ecologically or Biologically Significant Marine Areas; UNEP/CBD/RW/EBSA/SIO/1/4; CBD: Montreal, QC, Canada, 26 June 2013.

18. CBD. Report of the Arctic Regional Workshop to Facilitate the Description of Ecologically or Biologically Significant Marine Areas; UNEP/CBD/EBSA/WS/2014/1/5; CBD: Montreal, QC, Canada, 20 May 2014.

19. CBD. Report of the Mediterranean Regional Workshop to Facilitate the Description of Ecologically or Biologically Significant Marine Areas; UNEP/CBD/EBSA/WS/2014/3/4; CBD: Montreal, QC, Canada, 22 May 2014.

20. CBD. Report of the South-Eastern Atlantic Regional Workshop to Facilitate the Description of Ecologically or Biologically Significant Marine Areas; UNEP/CBD/RW/EBSA/SEA/1/4; CBD: Montreal, QC, Canada, 26 April 2014.

21. CBD. Report of the Wider Caribbean and Western Mid-Atlantic Regional Workshop to Facilitate the Description of Ecologically or Biologically Significant Marine Areas; UNEP/CBD/SBSTTA/16/INF/7; CBD: Montreal, QC, Canada, 23 April 2012.

22. CBD. Report of the North-West Atlantic Regional Workshop to Facilitate the Description of Ecologically or Biologically Significant Marine Areas; UNEP/CBD/EBSA/WS/2014/2/4; CBD: Montreal, QC, Canada, 26 May 2014.

23. CBD. Report of the Scientific Experts' Workshop on Criteria for Identifying Ecologically or Biologically Significant Areas Beyond National Jurisdiction; UNEP/CBD/COP/8/INF/39; CBD: Montreal, QC, Canada, 8 March 2006.

24. Dearden, P.; Topelko, K.N. Establishing Criteria for the Identification of Ecologically and Biologically Significant Areas on the high Seas. In Background Paper for the CBD Expert Workshop on Ecological Criteria and Biogeographic Classification Systems for Marine Areas in Need of Protection; CBD: Montreal, QC, Canada, 2005.

25. CBD. Decision VIII/24, Section 42. In Decision Adopted by the Conference of the Parties to the Convention on Biological Diversity at Its Eighth Meeting; UNEP/CBD/COP/DEC/VIII/24; CBD: Montreal, QC, Canada, 15 June 2006.

26. CBD. Decision VIII/24, Sections 44(b) and 46. In Decision Adopted by the Conference of the Parties to the Convention on Biological Diversity at its Eighth Meeting; UNEP/CBD/COP/DEC/VIII/24; CBD: Montreal, QC, Canada, 15 June 2006.

27. International Union for Conservation of Nature-World Commission on Protected Areas. Establishing resilient marine protected area networks: Making it happen. In Proceedings of the International Union for Conservation of Nature-World Commission on Protected Areas, National Oceanic and Atmospheric Administration and The Nature Conservancy, Washington, DC, USA, 1 January 2008.

28. CBD. Report of Expert Workshop on Ecological Criteria and Biogeographic Classification Systems for Marine Areas in Need of Protection; UNEP/CBD/EWS.MPA/1/2; CBD: Montreal, QC, Canada, 13 November 2007. 
29. CBD. Decision IX/20, Section 18 and Annex I. In Decision Adopted by the Conference of the Parties to the Convention on Biological Diversity at Its Ninth Meeting; UNEP/CBD/COP/DEC/IX/20; CBD: Montreal, QC, Canada, 9 October 2008.

30. CBD. Decision IX/20, Sections 14 and 19. In Decision Adopted by the Conference of the Parties to the Convention on Biological Diversity at Its Ninth Meeting; UNEP/CBD/COP/DEC/IX/20; CBD: Montreal, QC, Canada, 9 October 2008.

31. FAO. International Guidelines for the Management of Deep-Sea Fisheries in the High Seas; Food and Agriculture Organization of the United Nations: Rome, Italy, 2009.

32. IMO. Revised Guidelines for the Identification and Designation of Particularly Sensitive Sea Areas; Resolution A.982(24); International Maritime Organization: London, UK, 2005.

33. Smith, C.R.; Gaines, S.; Friedlander, A.; Morgan, C.; Thurnherr, A.; Mincks, S.; Watling, L.; Rogers, A.; Clark, M.; Bernardino, A.; et al. Preservation reference areas for nodule mining in the clarion-clipperton zone: Rationale and recommendations to the International Seabed Authority. In Proceedings of the Workshop to Design Marine Protected Areas for Seamounts and the Abyssal Nodule Province in Pacific High Seas, University of Hawaii at Manoa, Honolulu, HI, USA, 23-26 October 2007.

34. Fishpool, L.D.C.; Heath, M.F.; Waliczky, Z.; Wege, D.C.; Crosby, M.J. Important bird areas criteria for selecting sites of global conservation significance. Important bird areas criteria for selecting sites of global conservation significance. In Proceedings of the 22 International Ornithological Congress, Durban, South Africa, 16-22 August 1998; Volume 69, p. 428.

35. Eken, G.; Bennun, L.; Brooks, T.M.; Darwall, W.; Fishpool, L.D.C.; Foster, M.; Knox, D.; Langhammer, P.; Matiku, P.; Radford, E.; et al. Key biodiversity areas as site conservation targets. Bioscience 2004, 54, 1110-1118. [CrossRef]

36. CBD. Report of the Expert Workshop on Scientific and Technical Guidance on the Use of Biogeographic Classification Systems and Identification of Marine Areas beyond National Jurisdiction in Need of Protection; UNEP/CBD/SBSTTA/14/INF/4*; CBD: Montreal, QC, Canada, 11 January 2011.

37. CBD. COP Decision X/2 Annex of the Conference of the Parties. In Decision Adopted by the Conference of the Parties to the Convention on Biological Diversity at Its Tenth Meeting; UNEP/CBD/COP/DEC/X/2; CBD: Montreal, QC, Canada, 29 October 2010.

38. CBD. COP Decision X/29, Section 4. In Decision Adopted by the Conference of the Parties to the Convention on Biological Diversity at Its Tenth Meeting; UNEP/CBD/COP/DEC/X/29; CBD: Montreal, QC, Canada, 29 October 2010.

39. Pennington, J.T.; Mahoney, K.L.; Kuwahara, V.S.; Kolber, D.D.; Calienes, R.; Chavez, F.P. Primary production in the eastern tropical Pacific: A review. Prog. Oceanogr. 2006, 69, 285-317. [CrossRef]

40. Langhammer, P.F.; Butchart, S.H.M.; Brooks, T.M. Key Biodiversity Areas. In Encyclopedia of the Anthropocene; Elsevier: Amsterdam, The Netherlands, 2018; pp. 341-345.

41. International Maritime Organisation. Revised Guidelines for the Identification and Designation of Particularly Sensitive Sea Areas; Resolution A.982(24); International Maritime Organisation: London, UK, 6 February 2006.

42. Steven, R.; Morrison, C.; Arthur, J.M.; Castley, J.G. Avitourism and Australian Important Bird and Biodiversity Areas. PLoS ONE 2015, 10, e0144445. [CrossRef] [PubMed]

43. Elahi, R.; Ferretti, F.; Bastari, A.; Cerrano, C.; Colloca, F.; Kowalik, J.; Ruckelshaus, M.; Struck, A.; Micheli, F. Leveraging vessel traffic data and a temporary fishing closure to inform marine management. Front. Ecol. Environ. 2018, 16, 440-446. [CrossRef]

44. Bastari, A.; Micheli, F.; Ferretti, F.; Pusceddu, A.; Cerrano, C. Large marine protected areas (LMPAs) in the Mediterranean Sea: The opportunity of the Adriatic Sea. Mar. Policy 2016, 68, 165-177. [CrossRef]

45. Coll, M.; Piroddi, C.; Albouy, C.; Ben Rais Lasram, F.; Cheung, W.W.; Christensen, V.; Karpouzi, V.S.; Guilhaumon, F.; Mouillot, D.; Palomares, M.L.; et al. The Mediterranean Sea under siege: Spatial overlap between marine biodiversity, cumulative threats and marine reserves. Glob. Ecol. Biogeogr. 2012, 21, 465-480.

46. Micheli, F.; Levin, N.; Giakoumi, S.; Katsanevakis, S.; Abdulla, A.; Coll, M.; Fraschetti, S.; Kark, S.; Koutsoubas, O.; Mackelworth, P.; et al. Setting priorities for regional conservation planning in the Mediterranean Sea. PLoS ONE 2013, 8, e59038. [CrossRef] [PubMed]

47. Cerrano, C. Adriatic Sea: Description of the Ecology and Identification of the Areas that Mayde Serve to be Protected; Cerrano, C., Ed.; UNEP/MAP-RAC/SPA: Tunis, Tunisia, 2015; p. 92. 
48. Wang, Y.B.; Miao, J.L.; Zang, J.Y. Endangered species of marine organisms and its protection in China. Chin. J. Nat. 2010, 33, 137-142.

49. CBD. Azores Scientific Criteria and Guidance for Identifying Ecologically or Biologically Significant Marine Areas and Designing Representative Networks of Marine Protected Areas in Open Ocean Waters and Deep-Sea Habitats; Convention on Biological Diversity: Montreal, QC, Canada, 2009; pp. 1-11.

50. Smith, C.R.; Amon, D.; Altamira, I.; Thurnherr, A. Ecosystem Characteristics of Abyssal Nodule Fields, Especially the CCZ, Relevant to IRZs-PRZs. In Proceedings of the International Seabed Authority Workshop on the Design of Impact Reference Zones and Preservation Reference Zones, Berlin, Germany, 27-29 September 2017.

C 2019 by the authors. Licensee MDPI, Basel, Switzerland. This article is an open access article distributed under the terms and conditions of the Creative Commons Attribution (CC BY) license (http://creativecommons.org/licenses/by/4.0/). 